\title{
Pediatric Neurocritical Care
}

\author{
Sarah Murphy
}

Published online: 20 December 2011

(C) The American Society for Experimental NeuroTherapeutics, Inc. 2011

\begin{abstract}
Pediatric neurocritical care is an emerging multidisciplinary field of medicine and a new frontier in pediatric critical care and pediatric neurology. Central to pediatric neurocritical care is the goal of improving outcomes in critically ill pediatric patients with neurological illness or injury and limiting secondary brain injury through optimal critical care delivery and the support of brain function. There is a pressing need for evidence based guidelines in pediatric neurocritical care, notably in pediatric traumatic brain injury and pediatric stroke. These diseases have distinct clinical and pathophysiological features that distinguish them from their adult counterparts and prevent the direct translation of the adult experience to pediatric patients. Increased attention is also being paid to the broader application of neuromonitoring and neuroprotective strategies in the pediatric intensive care unit, in both primary neurological and primary non-neurological disease states. Although much can be learned from the adult experience, there are important differences in the critically ill pediatric population and in the circumstances that surround the emergence of neurocritical care in pediatrics.
\end{abstract}

Keywords Pediatric neurocritical care $\cdot$ Children $\cdot$ Pediatric TBI $\cdot$ Childhood stroke $\cdot$ Neuroprotection $\cdot$ Nonconvulsive seizures

S. Murphy

MassGeneral Hospital for Children,

Boston, MA 02114, USA

S. Murphy $(\bowtie)$

Harvard Medical School,

Boston, MA 02114, USA

e-mail: samurphy@partners.org

\section{Introduction}

Brain injury is common in childhood. Five times as many children will die from brain injury than from childhood cancer [1]. Neurological disorders, including both primary neurological diagnoses and neurological complications of critical illness, are frequently encountered in the pediatric intensive care unit (PICU). Reported experience with pediatric neurocritical care consultation services suggest that nearly one quarter of patients admitted to the PICU have, or are considered to be at risk for acute neurological injury [2]. PICU patients with neurological injury also have higher mortality, more long-term morbidity, and longer length of hospital stay [3]. A recent study found that more than half of the patients who died in a tertiary care center PICU had an acute brain injury. In $90 \%$ of these patients, brain injury was considered to be the proximate cause of death [4]. As advancements in diagnoses and therapies for lung, heart, kidney, and infectious disease have dramatically reduced mortality rates in the PICU, the relative contribution of neurological illness to mortality and long-term morbidity after critical illness has grown [5].

Traumatic brain injury (TBI) constitutes a significant portion of PICU admissions and remains a tremendously important issue in pediatrics and a major societal concern. TBI is the leading cause of mortality in children $>1$ year of age. Hospitalization for pediatric TBI alone accounts for greater than $\$ 1$ billion in hospital charges annually in the United States [6]. In spite of the importance and the appropriate emphasis on pediatric TBI in the field of pediatric critical care, the acute neurological injuries cared for in the PICU are heterogeneous. Along with trauma, status epilepticus, and post-neurosurgical diagnoses, primary non- 
neurological medical illnesses (including respiratory failure, cardiovascular illness, and shock) made up one-third of the pediatric neurocritical care consults in published experiences [2].

Pediatric stroke is also recognized as an important cause of childhood disability and long-term neurological morbidity. The publication of guidelines for the acute management of stroke in pediatric patients, investigations into a potential role for thrombolysis in pediatric stroke, and observations from the adult stroke experience have contributed to a dialogue as to whether pediatric stroke care, such as adult stroke care, may benefit from specialized stroke services or stroke centers.

In this article, the reader will be introduced to major developments in the field of pediatric neurocritical care; however a comprehensive review of the field is beyond the scope of this article. This article focuses on current controversies in pediatric TBI and pediatric stroke with an emphasis on how these diseases differ in children as compared with adults. In addition, this article discusses neuromonitoring and neuroprotection in pediatric critical illness, including the concept of cardiocerebral resuscitation in children. Finally, in this article, it is considered how these issues are stimulating the field of pediatric neurocritical care and describes some of the questions regarding the emerging practice of pediatric neurocritical care itself.

\section{TBI}

The Kennard principle is the idea that the immature brain, having a greater degree of neural plasticity than an adult brain, also has a greater ability to recover from injury. Following work in the primate models of focal cortical injury, early studies of TBI in children lent support to the effect of the Kennard principle and the general thinking that children had better outcomes than adults [7]. Subsequently, tremendous variability in outcome following an early brain insult has been described [8]. Plasticity, or the ability of the brain to dynamically respond to input and experience by modifying neural circuitry, may make possible both "good" or "bad," maladaptive, changes. Neural plasticity involves complex molecular, cellular, and biomechanical events. Injury that results in altered neurotransmission, neuronal death, or changes in neural connectivity can disrupt or even derail these unfolding processes. Diffuse injury, for example, may interrupt the development of diffuse neural networks in a developing brain or overwhelm the ability of the brain to support adaptive plasticity $[8,9]$. It is suggested from studies of animal models that timing of injury may be a critical factor. There seem to be critical periods of heightened plasticity when certain defined brain areas may be selectively vulnerable [10]. The enhanced plasticity of a developing brain may therefore confer unique vulnerabilities in addition to opportunities for therapeutic intervention [11].

Contrary to traditional thinking, outcome following TBI in children may not be better than in adults $[12,13]$. Children who suffer a TBI have significant, long-term cognitive and behavioral disturbances, and more limited recovery of function than was previously appreciated. In comparison to their peers, children who have experienced a TBI have lower scores on measures of intelligence, impaired executive functioning, decreased attention, poor academic achievement, and notably they lack "catch-up" in long-term studies [14-16]. Morbidities may not manifest for many years after the insult, when the patient fails to make expected developmental gains and "grows into" their injury.

\section{How is TBI Different in Children?}

Mechanisms of TBI differ by age. In toddlers and young school-aged children, falls are the most common reason for TBI-related hospitalization, whereas bicycle and motor vehicle accidents are the most important cause of TBI in older children and adolescents. Unique to pediatrics is inflicted traumatic brain injury (iTBI), a major cause of TBI in young patients [17]. Inflicted injury is associated with worse outcome compared to accidental trauma and represents a disproportionate number of deaths in the patients 2 years of age [18-21]. Different biomechanical mechanisms of injury, exposure to multiple repeated insults, younger age of patients, and secondary injury factors, such as hypoxia and seizures, have all been proposed as potential factors.

Inflicted TBI has been defined as an intentional injury characterized by the triad of subdural hemorrhage, retinal hemorrhage, and encephalopathy. Subarachnoid hemorrhages and hypoxic ischemic injury are also commonly seen $[22,23]$. It has been postulated that hypoxic-ischemic injury with iTBI may be related to apnea from traumatic injury to the brainstem or rotational acceleration-deceleration forces causing deep focal injuries that might contribute directly to cardiorespiratory compromise [24]. Despite well-described radiographic features and imaging patterns of inflicted injury, diagnosis of inflicted brain injury is difficult in practice and highly controversial. Isolated clinical factors, radiological findings, or other diagnostic tests are unable to reliably distinguish inflicted from accidental injury [25-27].

Serum and cerebrospinal fluid (CSF) biomarkers have been a recent focus of research. These may have potential to act as markers of injury severity or predict outcome in patients with TBI [28-30]. In addition, biomarkers have been studied as a means to differentiate inflicted trauma 
from accidental trauma, to elucidate differences in the pathophsyiology of these injury types, and to serve as a screening tool for the diagnosis of iTBI [30-35]. These studies provide further evidence that the biochemical response to inflicted TBI may be different from noninflicted injury. CSF biomarkers with iTBI are consistent with a greater degree of hypoxic-ischemic injury [30, 34]. This remains an active area of research.

There appears to be age-related differences in the response to injury of the brain. Clinically, younger age is associated with a higher incidence of subdural hematomas, diffuse injury, and edema [36, 37]. In young children, infants and toddlers, a unique pattern of rapidly developing unilateral or bilateral supratentorial tissue loss has been described in association with acute subdural hematoma, the pathophysiology of which is incompletely understood [38]. In adolescence contusions and axonal injury are common, consistent with adult patterns of injury [39].

Although not unique to pediatric brain injury, diffuse brain swelling is an important feature of pediatric TBI and has been reported to be 3 times as common in pediatric TBI as compared with adult TBI [40, 41]. Diffuse cerebral swelling has been associated with rapid neurological deterioration and is the most common cause of brain death following severe TBI in both children and adults [42]. The mechanisms underlying this phenomenon are not fully understood [43]. Although initially attributed to increased cerebral blood flow (CBF) and vascular engorgement [44, 45], better characterization of $\mathrm{CBF}$ in healthy and injured children has shown a more heterogeneous cerebrovascular response to injury in pediatric patients [46]. Cerebral hypoperfusion is likely the dominant derangement and there may be a greater risk of hypoperfusion following injury in the youngest victims [47-50]. In children, as in adults, low CBF has been associated with worse outcome.

Other factors may contribute to diffuse swelling in pediatric TBI. Differences in the material properties of the adult and pediatric skull, for example, may play a role. A fully mature, adult skull will deform very little prior to fracture. In contrast, the pediatric skull is thinner and relatively more compliant. Membranous cranial sutures add additional elastic properties which, taken together, allow the pediatric skull to deform to a much greater extent before breaking [51-53]. Simulations using porcine and anthropomorphic models of pediatric brain trauma have demonstrated large cranial shape changes and a more diffuse pattern of brain distortion in response to blunt trauma in young children than is seen in adults. In addition, there are developmentally regulated discrepancies in the water content and degree of myelination in the brain, which may also contribute to a more diffuse transmission of traumatic forces throughout the brain tissue [54].
Apoptotic cell death is a normal part of brain maturation and remodeling. It has been argued that a propensity for apoptosis may distinguish the response to injury in the developing brain. Pre-clinical data comes from neonatal head-injured rats, in which apoptotic cell death contributes to neuronal injury in an age-dependent fashion and is the predominant mechanism of cell death in the most vulnerable ages [54]. The period of enhanced vulnerability coincides with a time of synaptogenesis and rapid brain growth - a comparable period in humans begins prenatally, which continues for several years after birth [55].

CSF and serum biomarker studies have lent support for the potential importance of apoptosis in young patients with brain injury. Decreased CSF levels of anti-apoptotic proteins and increased CSF levels of pro-apoptotic proteins have been found in children following TBI [56]. A delayed increase in CSF levels of neuron-specific enolase, suggestive of apoptotic cell death, has also been described $[41,57]$. More recently, a serum biomarker "trajectory," with late or sustained increases in neuron-specific enolase and consistent with apoptotic or delayed cell death, has also been demonstrated. This "late-rising" trajectory was associated with poor outcome, although the trajectories were unable to differentiate injury mechanisms (TBI $v s$ hypoxic-ischemic injury) [58]. Whether these findings reflect secondary injuries, apoptotic processes, or another mechanism of delayed cell death is not known. Biomarkers are being intensely studied as a means of illuminating secondary injury mechanisms, to search for potential therapeutic targets in injury cascades, to assess response to therapies, and as a tool for predicting outcome [30, 59].

\section{Current Controversies}

Important areas of investigation in the clinical management of pediatric TBI include the incorporation and integration of advanced neuromonitoring into the care of pediatric patients and ongoing evaluation of standard treatments and novel therapies for pediatric TBI. Over the past decade, many new technologies that can be used to monitor brain physiology and function have been introduced into intensive care units. These include brain-tissue oxygen monitoring, transcranial Doppler ultrasound, and near-infrared spectroscopy. An area of interest in pediatrics has been the use of neuromonitoring to describe cerebral hemodynamics and cerebral autoregulation following brain injury.

Impaired cerebral autoregulation is common following TBI and has been reported in 29 to $63 \%$ of pediatric patients [60-63]. Young age (less than 5 years) appears to be a risk factor $[64,65]$. Several studies have linked impaired cerebral autoregulation with poor outcome $[61,66,67]$. A recent 
study found only low systolic blood pressure and impaired cerebral autoregulation to be independently associated with poor outcome after multivariate analysis of multiple hemodynamic factors [68]. It remains unclear if impaired autoregulation is a simply a marker of injury severity or an independent causal factor.

While defining physiologic targets, such as systolic blood pressure (SBP), intracranial pressure (ICP), and cerebral perfusion pressure (CPP), remains controversial in the management of adult patients with severe TBI, in pediatric patients the problem is further complicated by a background of development-related variation in these physiological parameters. For example, the 2003 "Guidelines for the Acute Medical Management of Severe TBI in Infants, Children, and Adolescents" recommends maintaining a CPP of $>40 \mathrm{mmHg}$ in pediatric patients while acknowledging that a minimal acceptable CPP likely exists along an age-related gradient [69]. Since that writing, refined minimum CPP goals have been suggested for pediatric patients in 3 age brackets: 1) $53 \mathrm{mmHg}$ for patients 2 to 6 years, 2) $63 \mathrm{mmHg}$ for patients 7 to 10 years, and 3) $66 \mathrm{mmHg}$ for patients 11 to 16 years [70]. No data exists for the youngest patients (those less than 2 years of age) who continue to have the worst outcomes. The pediatric guidelines recommend the treatment and avoidance of hypotension, defined as a SBP less than the 5th percentile by age. At least one study has shown poor outcome [71] to be independently associated with a $\mathrm{SBP}<75 \%$ of normal for age. Against this backdrop, advanced monitoring strategies (such as techniques to monitor the strength of autoregulation or cerebral oxygenation) present potential opportunities to titrate treatments to more directly meaningful physiological and therapeutic goals.

Brain tissue oxygen tension ( $\mathrm{PbtO} 2)$ has been investigated in multiple pediatric studies [62, 72-79] and has been shown to be an independent predictor of poor outcome in pediatric TBI [80]. One study found that even when goal therapeutic targets were met, including ICP $<$ $20 \mathrm{mmHg}, \mathrm{CPP}>50 \mathrm{mmHg}, \mathrm{PaO} 2>60 \mathrm{mmHg}$, peripheral oxygen saturation $>90 \%$, and hemoglobin $>8 \mathrm{~g} / \mathrm{dl}, 80 \%$ of monitored patients experienced one or more episodes of compromised cerebral oxygenation $(\mathrm{PbtO} 2<20 \mathrm{mmHg}$ ). Almost one-third experienced episodes of brain hypoxia (defined as $\mathrm{PbtO} 2<10 \mathrm{mmHg}$ ) [73]. These studies offer a compelling data suggesting that brain tissue oxygen monitoring may be useful in guiding the management of pediatric patients with TBI. A study assessing the effect of preventing or aggressively treating cerebral hypo-oxygenation on outcome in severe TBI in children has not been published.

In 2003, the "Guidelines for the Acute Medical Management of Severe TBI in Infants, Children, and Adolescents" were published. Most recommendations are at an "Option" or "Class III" level of evidence. The guidelines are based largely on data extrapolated from adult studies, with little evidenced-based data from pediatric trials to guide their writing and few specific standards of care set. Since 2003, many more pediatric-specific studies in TBI and more than 100 review articles have been published. Updated treatment guidelines are expected at the time of this writing. This article will briefly discuss 2 important topics: 1) hypothermia and 2) decompressive craniectomy.

\section{Hypothermia}

Although there has been great interest in the potential therapeutic effect of induced hypothermia in pediatric TBI, conclusively demonstrating a benefit has remained elusive. Brain swelling is an important problem in pediatric TBI, and hypothermia has been shown to reduce intracranial pressure in adult and pediatric patients and to reduce cerebral swelling in animal models [81, 82]. Induced hypothermia has also been shown to decrease mortality and improve outcome in neonates with hypoxic-ischemic injury [83]. In addition, early unintentional hyperthermia is common in pediatric TBI and has been associated with worse outcomes [84]. Finally, although a large, randomized controlled trial in adults following TBI found no benefit to moderate $\left(33^{\circ} \mathrm{C}\right)$ cooling within 8 hours of injury [85], subgroup analysis suggested a trend toward benefit in younger patients $(<45$ years $)$ who were admitted with low temperature [86]. This evidence fueled hope for a potential role of early hypothermia therapy in pediatric TBI.

In 2008, the results of a large, multicenter, pediatric, randomized controlled trial were published and failed to demonstrate any benefit to induced moderate hypothermia (goal $32.5^{\circ} \mathrm{C}$ for $24 \mathrm{~h}$ ) in pediatric patients with severe TBI [87]. A trend toward worsening, with a higher rate of unfavorable outcomes, was seen in the hypothermia group. The short duration of cooling has been criticized, given concurrent research, which seemed to show limited benefit and rebound intracranial hypertension when hypothermia therapy is used for shorter durations $(<48-72 \mathrm{~h})$. In addition, retrospective analysis found higher incidences of hypotension and low cerebral perfusion pressure in the treatment as compared with the control group [88]. In 2011, a second, large, multicenter trial of hypothermia with severe TBI in children, led by the Pediatric TBI Consortium trial halted enrollment. The study protocol attempts to address many of the concerns raised by the Canadian Trials study, including a longer duration of cooling, slower re-warming protocol, and careful monitoring for and treatment of hypotension [42]. Results from this trial are awaited.

\section{Decompressive Craniectomy}

Multiple retrospective reviews and small case series have described beneficial effects of decompressive craniectomy 
(DC) following TBI in children [89-96]. A single, prospective, randomized controlled trial has been published. This small study enrolled 27 patients for a 7-year period. Thirteen patients randomized to DC had improved favorable outcome at 6 months as compared with those who were managed medically (54\% vs $14 \%)$ [97]. A recent metaanalysis of DC in pediatric patients that included 172 patients from 35 studies concluded that DC might be warranted in pediatric patients with high ICP from any etiology. Of the 135 patients with TBI who underwent DC, $60 \%$ had favorable outcome. The timing of DC (within $24 \mathrm{~h}$ ) was not significantly associated with favorable outcome on multivariate analysis, although data on the timing of the surgery was limited [98]. In addition to improving ICP, DC has also been shown to improve cerebral oxygenation in pediatric patients with TBI [75, 99]. The recently published "Decompressive Craniectomy in Diffuse TBI" and the Randomised Evaluation of Surgery with Craniectomy for Uncontrollable Elevation of Intra-Cranial Pressure (RESCUEicp) trials in adults may lay the groundwork for a similar study to be performed with pediatric patients [100]. Large, randomized trials in pediatric patients that address long-term outcomes, including quality of life measures, are needed to address optimal patient selection, timing of intervention, and surgical methods.

\section{Pediatric Stroke}

Pediatric stroke is an important cause of childhood disability, occurring at least as frequently as pediatric brain tumors [101]. Despite efforts to raise public awareness, strokes in children are under-recognized and long-term morbidities may be underappreciated. The reported incidence of stroke in children ranges from 2 to 13 per 100,000 children per year, an estimate that has increased with time as newer imaging techniques have improved diagnosis [102]. The incidence in neonates is highest. Perinatal stroke, defined as cerebrovascular events that occur between 28 weeks of gestation and 28 days of postnatal age, may have an incidence as high as 1 in 4000 live births. Perinatal strokes have a unique presentation and risk factors, and comprise a significant portion of pediatric stroke taken as a whole [103]. In adults, ischemic strokes predominate, whereas in children, intracerebral hemorrhage and ischemic stroke are more evenly represented [104-107]. Cerebral sinovenous thrombosis is most common in the neonatal population and has a reported incidence of 1 of 100,000 children per year [108].

Pediatric stroke is associated with a significant cost to the individual and to society. The idea that children have excellent recovery has been well contradicted: 5 to $10 \%$ of children will die from acute stroke complications; stroke recurs in as many as one third of these children and $\geq 70 \%$ of the patients will have seizures or other long-term neurological deficits [109] [103]. The estimated annual cost of acute pediatric stroke care in the United States is $\$ 42$ million. The mean cost of acute hospital care is $>\$ 20,000$ per patient [110].

\section{How is Stroke in Children Different?}

Challenges in pediatric stroke care include well-described delays in diagnosis and the pressing need for well-designed pediatric clinical studies that can support evidence-based treatment decisions.

The diagnosis of stroke in children is frequently delayed. The time to establishing a diagnosis of arterial ischemic stroke (AIS) in children averages $>24$ hours and is even longer in neonates [111-115]. Both pre-hospital and inhospital delays have been identified. A lack of recognition of stroke symptoms in children may contribute to a $>24-$ $\mathrm{h}$ delay from symptom onset to the time of seeking medical treatment that has been seen in some studies $[112,116]$. Adult risk factors that are typically associated with stroke (including hypertension, hyperlipidemia, diabetes, and atherosclerosis) are rare in pediatrics. By contrast, factors associated with childhood stroke include congenital heart disease, head and neck trauma, sickle cell anemia, genetic and metabolic diseases, prothrombotic abnormalities, and infection.

Recent studies however have focused attention on significant in-hospital delays in the diagnosis of pediatric stroke. In a retrospective review of more than 200 children with AIS, Rafay et al. [117] found a relatively brief delay between onset of symptoms and seeking medical care $(1.7 \mathrm{~h})$, but a greater than 12-h delay in the hospital to the time of diagnosis. In this study, as in others, clinical suspicion for AIS among healthcare providers was low, documented in only $38 \%$ of patients after initial evaluation. A separate retrospective study examining time to diagnosis in more than 100 pediatric patients also found a low level of suspicion of stroke among medical providers. The correct diagnosis was suspected on initial assessment in only a minority of children who were ultimately diagnosed with AIS (26\%). In this study, $86 \%$ of the patients had focal neurological deficits and more than half of the patients (58\%) were admitted to the hospital at the time of their symptom onset [111]. In spite of this, median time to diagnosis was greater than $24 \mathrm{~h}$ for children with stroke and greater than $87 \mathrm{~h}$ in neonates.

Although nonfocal neurological signs (such as seizures, altered mental status and irritability) occur frequently in childhood stroke, hemiparesis is the most common presentation of AIS in children and middle cerebral artery territory is the most common location for infarct [109]. Focal motor weakness is the initial symptom in the majority $(70-80 \%)$ of pediatric AIS patients $[115,118]$. Recent studies have not 
found an association between the presenting clinical symptom and the length of delay in medical evaluation or diagnosis of stroke $[111,116]$.

Time-consuming evaluations to exclude alternative diagnoses and "stroke mimics" likely play a role [109, 119]. Many mimics of childhood stroke have been described. A case series of 143 patients evaluated by an acute pediatric stroke service found that $20 \%$ of patients referred had stroke mimics [120]. The description of stroke mimics is somewhat restricted in that the investigators were only able to describe patients who were referred to the stroke service, and thus missed patients in whom the initial healthcare provider had a low clinical suspicion. Stroke mimics included benign (migraine, psychogenic, musculoskeletal) and "not benign" diagnoses, such as posterior reversible leukoencephalopathy, seizures, vascular anomalies, and tumor. The frequency of stroke mimics and relative rarity of stroke in childhood likely confound rapid diagnosis in children.

Of particular difficulty may be diagnosing stroke in patients who present with a seizure. Seizure is a common presentation of stroke in children, seen in 20 to $44 \%$ of patients with AIS and $>20 \%$ of patients with intracerebral hemorrhage [121, 122]. Seizures appear to be more common in pediatric as compared with adult stroke although data are somewhat conflicting $[123,124]$. Seizures may be associated with young age and are the most common presenting finding in infants [125]. One small study examining misdiagnoses in pediatric stroke found that a significant percentage of the patients who were misdiagnosed had hemiparesis or aphasia from AIS that was attributed to a post-ictal state [119].

There are also significant delays in obtaining imaging in pediatric stroke patients. The computed tomographic (CT) scan, which is the standard initial neuroimaging test for patients with acute neurological presentations, is performed within 6 hours from the onset of symptoms in only a minority of stroke patients. Even then, the sensitivity of the CT scan in diagnosing AIS is low. Published studies have shown that CT misses the diagnosis of AIS in the majority of pediatric patients $(52-84 \%)$ [108, 117]. Definitive neuroimaging using magnetic resonance imaging often requires that young children be sedated. Magnetic resonance imaging is typically delayed to a great extent and takes more than 24 hours to complete in the majority of patients $[113,117]$.

\section{Current Developments}

Advancements in pediatric stroke care have been hampered by the lack of understanding regarding the underlying pathophysiological mechanisms and a paucity of prospective data regarding treatment and outcomes. Currently, there are no proven strategies for the medical management of childhood stroke, outside of blood transfusion for children with sickle cell anemia. Recommendations and treatment guidelines have largely been extrapolated from adult data. Three guidelines exist to guide the management of pediatric stroke, including the American College of Chest Physicians Guidelines [126], the American Heart Association Guidelines [127], and the Royal College of Physicians guidelines from the United Kingdom. Recommendations in these guidelines are based on an expert and consensus opinion, and in some instances are diverging in their interpretation of the data and on specific clinical management points [128].

In 2002, The International Pediatric Stroke Study (IPSS) group was formed as a multicenter, prospective childhood stroke registry with the purpose of supporting studies in childhood stroke. The first initiative was to develop protocols that would enable standardized data collection across participating sites, including variables relating to the diagnosis, investigation, treatment, and outcome of children with stroke. In addition, a pediatric adaptation of the National Institutes of Health Stroke Scale (PedNIHSS) was created to assist in standardizing studies. This scale has demonstrated good inter-rater reliability in a multicenter study. The next step will be validation with analysis of outcome measures [129].

In the intervening years, the IPSS has expanded from 9 to more than 60 centers spanning 17 countries with 76 coinvestigators [130] and fostered the formation of a multinational collaboration of investigators interested in childhood stroke. This has already led to the initiation and publication of several important studies that attempt to address critical gaps in knowledge in the field of pediatric stroke.

Among other studies initiated by the IPSS group, there have been surveys of current practices in pediatric stroke care. These have described the use of alteplase in childhood arterial ischemic stroke and the predictors of antithrombotic treatment in neonatal cerebral sinovenous thrombosis (CSVT) [131, 132]. These have highlighted the variability and inconsistencies in different areas of pediatric stroke practice and underscored the lack of evidence-based guidance in pediatric stroke management. Although there are currently no recommendations for its use, alteplase is regularly given to children at time intervals that fall outside the recommended adult guidelines in varying doses [131]. Development-related differences in the coagulation system, in stroke pathophysiology, and in neuropharmacology limit the ability to directly translate adult experience to pediatrics [133]. Evidence for the safety and efficacy of thrombolysis in children is currently limited to case reports.

Intracerebral and subarachnoid hemorrhage account for $40-50 \%$ of childhood stroke. Recent studies have characterized risk factors and presenting symptoms in children. Vascular anomalies, including arteriovenous malformations, 
arterial-venous fistulas, and aneurysms appear to be the most common factor and are associated with 42 to $90 \%$ of cases [134-136]. Other important factors include brain tumors $(9-13 \%)$ and medical illnesses $(23-32 \%)$. In a significant number no etiology can be identified (19\%) [134]. In children $>5$ years of age, headache and focal neurological deficits appear to be the most frequent presenting symptoms. In young children, however, presentations are more often nonspecific, including changes in mental status and onset of seizure. In most cases, the evolution of symptoms is brisk [134].

Cerebral arteriopathy is now recognized as an important cause of pediatric AIS and has been the focus of recent investigation. Arteriopathies has been identified up to $60 \%$ of pediatric patients with AIS [137]. The presence of arteriopathy strongly predicts stroke recurrence [138]. Known arteriopathies include Moyamoya disease, arterial dissection, and vasculitis. Recently, a focal cerebral arterial stenosis without an apparent cause or an associated illness has also been described [137]. Described in previous studies as "transient cerebral arteriopathy," these characteristically involve the distal internal cerebral artery, proximal middle cerebral artery, or the proximal anterior cerebral artery unilaterally, and they stabilize or improve after a 6-month period [139]. The pathophysiology underlying these descriptive findings is not known. Recent upper respiratory infection has been identified as a risk factor [137]. Angiopathy following varicella infection has been previously associated with ischemic stroke in adults and children, as with other viruses that have been linked in case reports to ischemic stroke in children [139]. The role infection may play in pediatric arterial ischemic stroke is an area of active research [140].

Two recent studies have considered a potential role for continuous electroencephalographic (cEEG) monitoring in the management of pediatric stroke. An exploratory study designed to identify risk factors for seizures included 60 pediatric patients with AIS, and $20 \%$ of those presented with seizures, all with concurrent hemiparesis. Although cEEG was not routinely performed, nonconvulsive seizures (NCS) were identified in 3 of 4 patients who underwent cEEG monitoring for altered mental status. Seizures were not associated with infarct location, but they were seen more commonly in children less than 4 years of age [121]. A second study evaluated risk factors for seizures in 88 patients admitted to a tertiary care center pediatric intensive care unit (PICU) with a diagnosis of stroke. In this cohort $68 \%$ of patients had AIS, $14 \%$ had cerebral sinovenous thrombosis (CSVT), and $18 \%$ had an intracerebral hemorrhage. Overall, $21 \%$ of the patients presented with seizure and an additional $10 \%$ had seizures within $24 \mathrm{~h}$ of presentation. There were $14 \%$ of patients who underwent cEEG monitoring were found to have NCS, all were in nonconvulsive status epilepticus (NCSE). Finally, in the absence of guidelines, 21\% of patients who did not have seizures during their acute hospitalization were discharged on anticonvulsant medications [122]. The role of monitoring for NCS in pediatric stroke and other PICU patients will be discussed as follows.

\section{Neuromonitoring and Neuroprotection in the PICU}

Recent publications have drawn attention to the prevalence of neurological morbidity following critical illness in pediatric patients and the importance of brain injury as a contributing cause of death in the PICU [3, 4, 141, 142]. These studies highlight the opportunity for development and implementation of neuroprotective strategies in a wide variety of illnesses that are encountered in the PICU. Neuromonitoring might logically accompany neuroprotection strategies in patients who are thought to be at risk. Neurological dysfunction is not routinely monitored beyond basic neurological examinations. Many critically ill pediatric patients require medications for sedation that further limit the sensitivity of these examinations. Noninvasive monitoring may include near infrared spectroscopy, transcranial Doppler, or continuous electroencephalography, among other monitoring.

A recent focus of neuromonitoring in both adults and pediatrics has been diagnosing NCS and NCSE. Studies in the adult population have included patients with TBI, sepsis, central nervous system infection, stroke, subarachnoid and intracranial hemorrhage, patients undergoing induced hypothermia following cardiac arrest, and patients with otherwise unexplained alterations in mental status. Between 8 and $48 \%$ of these select patient populations have been found to have NCS [143]. Younger age has been suggested as a risk factor $[144,145]$. NCS have been associated with increased neurological morbidity and may be an under-recognized neurological insult in critical illness [146, 147]. The benefit of detecting or treating clinically silent seizures is unproven.

Several retrospective studies that describe findings in pediatric patients who have undergone cEEG monitoring have been published [144, 148-153]. The clinical characteristics of the patients vary and include patients being monitored following clinical seizures and patients with changes in mental status without overt seizure activity. They include patients with epilepsy, hypoxic-ischemic injury or stroke, TBI, and metabolic disease. The incidence of NCS in these studies varies widely from 16.3 to $39 \%$ [144, 150, 152, 154]. Adding to this literature, 2 recent, prospective pediatric studies have been published. Abend et al. [123] found NCS or NCSE in nearly half $(46 \%)$ of 100 patients who underwent cEEG monitoring in accordance with predetermined clinical practice guidelines from their institution. The majority of patients with NCS had NCS exclusively. In contrast, using strict enrollment criteria (consecutively 
admitted patients with a Glasgow Coma Scale of $<8$ and not rapidly improving, as after anesthesia) Shahwan et al. [155] diagnosed NCS in only 7 of 100 pediatric patients, and 6 of these had witnessed clinical seizure activity prior to initiating the monitoring. Although patient characteristics may partially explain these discrepancies, they also suggest that without rigorous enrollment criteria it may be very difficult to circumvent the introduction of ascertainment bias into such studies [147].

It is likely that given current practices, NCS and NCSE are being missed in some critically ill pediatric patients. A common theme in published studies is that the majority of pediatric patients who have NCS appear to have nonconvulsive seizures exclusively [123, 144, 152]. In addition, half of the NCS will not be diagnosed with routine 60-minute electroencephalographic monitoring and up to one-fifth of patients will require monitoring for greater than $24 \mathrm{~h}$ to make the diagnosis [144]. Prospective studies for welldefined cohorts of at-risk patients, including patients with TBI, sepsis, and stroke are needed to better define the prevalence of NCS and NCSE, and to aid in the creation of practice guidelines for the use of cEEG monitoring in the pediatric intensive care unit. Such a study has already been published for pediatric patients undergoing induced hypothermia after cardiac arrest. Electrographic seizures were found in nearly half (47\%) of the patients enrolled [156].

Against these concerns, another must be weighed, as there is a growing body of literature in experimental animals on the developmental neurotoxicity of many sedation medications that are used in the intensive care unit. Exposure to drugs that inhibit N-Methyl-D-aspartate-type glutamate receptors or that activate gamma-aminobutyric acid receptors has been shown to lead to widespread and dose-dependent neurological cell death and long-lasting neurocognitive deficits in developing animal models [157]. Neurotoxicity may be enhanced during certain critical periods of brain development [55]. Evidence has suggested that even brief exposures to anti-excitatory, neurotransmitter-blocking medications might cause increased apoptotic cell death and cognitive impairment in animals. There are known cognitive impairments in children treated with long-term anticonvulsants [39]. The indications for anti-seizure treatment will need to be clarified, along with efforts to understand the effects of treatment on long-term cognitive outcomes.

\section{Advances in Cerebral Resuscitation in Children}

The need for cerebral protection strategies for children following a cardiac arrest is most apparent. Although the return of spontaneous circulation is seen in 30 to $65 \%$ of pediatric patients following a cardiac arrest (more commonly found in-hospital cardiac arrest) long-term survival with good neurological recovery that may be achieved in only a minority [158-160]. Common causes of death in nonsurvivors are brain death or neurological futility, particularly among patients who have an out-of-hospital arrest [161]. Neuroprotective strategies in pediatric cardiac arrest include induced hypothermia and extracorporeal cardiopulmonary resuscitation (ECPR).

Hypothermia to $32^{\circ} \mathrm{C}$ to $34^{\circ} \mathrm{C}$ for adult patients following a cardiac arrest has been proven beneficial in terms of both survival and neurological outcome [162, 163]. Pediatric cardiac arrest, however, is a distinct entity. Unlike adult cardiac arrest, the majority of pediatric cardiac arrest occurs second to respiratory failure or circulatory shock, with a preceding period of hypoxia-ischemia that likely compounds the neurological insult. The presenting rhythm is most commonly asystole or pulseless electrical activity, with ventricular fibrillation or pulseless ventricular tachycardia being relatively rare $(7-10 \%)[164,165]$. Although hypothermia following nonshockable adult cardiac arrest is not endorsed by current guidelines, a recently published systematic review and meta-analysis of induced hypothermia in nonshockable adult cardiac arrest patients lent support to the idea that hypothermia therapy might be associated with reduced in-hospital mortality in this population. However, the poor quality of evidence argued the need for a well-designed randomized controlled trial to address the question [166]. In addition, a contemporaneous study examining data from a large prospectively collected data registry included more than 400 adult patients presenting with asystole or pulseless electrical activity found no benefit from induced hypothermia in adult patients presenting with nonshockable rhythms and a possible association with harm [167].

The benefit of cooling pediatric patients following a cardiac arrest remains unproven. A review of the literature reveals 2 retrospective studies in pediatric patients. A single center, retrospective cohort study designed to describe the use and assess the feasibility of cooling found a mean target temperature of $34^{\circ} \mathrm{C}$ was obtained in $3 \mathrm{~h}$ and maintained for $24 \mathrm{~h}$ in the 40 patients treated with hypothermia. The majority of patients who were cooled presented with temperatures at or below the target temperature. The investigators observed no difference in mortality between the hypothermia and standard treatment groups, although the patients treated with hypothermia seemed to be more severely ill. Patients treated with hypothermia had a higher frequency of unwitnessed arrest and more doses of epinephrine required to achieve return of circulation [168]. A second retrospective, multicenter study showed similar results. Higher mortality was seen in 29 patients treated with hypothermia therapy when compared to those patients who received standard treatment. Patients treated with hypothermia had longer duration of cardiac arrest, more resuscitative efforts, higher lactate, and greater use of extracorporeal membrane oxygenation. After adjusting for these variables, there was no statistically 
significant difference in mortality between the hypothermia and standard treatment groups [169].

To date, no randomized controlled trials have been published. The groundwork for this study has been well built. Three large, retrospective cohort studies that included patients from 15 hospitals affiliated with the Pediatric Emergency Care Applied Research Network have examined the outcome and identified risk factors associated with poor outcome for both in-hospital and out-of-hospital pediatric cardiac arrest [161-171]. Surveys from the United Kingdom and the United States have demonstrated both variability in the practice of cooling, and a widespread willingness and interest in a randomized controlled trial to study its use [172, 173]. In addition, a single prospective study of cEEG monitoring in pediatric patients undergoing therapeutic hypothermia for cardiac arrest has demonstrated electrographic seizures in $47 \%$ of patients treated, the majority of which $(67 \%)$ were nonconvulsive [156]. This finding suggests another dimension of important related research. A multicenter trial of therapeutic hypothermia following pediatric cardiac arrest is currently underway.

Cardiopulmonary resuscitation enhanced or extended by extracorporeal membrane oxygenation (ECPR) was first used in children following cardiac surgery, and it is still largely used in pediatric patients with heart disease. Survival for pediatric patients has been reported as anywhere from 23 to $73 \%$ based on published, single-center experiences [174-182]. Two multicenter registry database analyses have also been performed. From the Extracorporeal Life Support Registry, Thiagarian et al. [183] found that overall survival to hospital discharge after ECPR was 38\%. Raymond et al. [184] analyzed the National Registry of Cardiopulmonary Resuscitation and found survival to discharge of $44 \%$, remarkably, with $95 \%$ reported having favorable neurological outcome. Neurological complications from ECPR, including hemorrhage, infarction, and brain death are common. There were 20 to $30 \%$ of patients undergoing ECPR who had an acute neurological complication, and mortality in this subset approaches $90 \%[185,186]$. Nonetheless, the percentages of patients reported to have "good" neurological outcome following ECPR in many studies have been excellent. One factor may be the characteristics of the patients who undergo ECPR, generally infants with congenital cardiac disease. More information is needed regarding long-term outcomes to help determine which patients may benefit and how best to use this therapy.

\section{Pediatric Neurocritical Care}

The establishment of the field of adult neurocritical care has brought the development of specialty care expertise, the dissemination of knowledge through neurocritical care training programs and peer-reviewed publications, the implementation of advanced monitoring techniques and protocol-driven therapies, and the creation of specialized neurocritical care units. These developments have led to improved outcomes in many types of neurological injury and illness and fueled basic science and clinical research that advances patient care $[187,188]$. The field of pediatric neurocritical care has no doubt been stimulated by these developments.

Although much can be learned from the adult experience, there may be challenges to translating this model into pediatrics. The needs of the adult and pediatric critical care populations may be different. In adults, a sufficient patient volume to support of dedicated neurointensive care units may exist, however, it is not clear if the number of pediatric patients requiring specialized neurocritical care services would justify this expenditure of resources, except in the largest of hospitals [189]. The cohorting of acute neurological emergencies, such as stroke and subarachnoid hemorrhage in the adult neurointensive care units has promoted standardization of care, development of treatment protocols, and the creation of evidence-based guidelines. This focused approach to clinical care and investigation needs to be replicated in pediatric-specific neurological diseases. The spectrum of neurocritical illness in the PICU, however, is diverse. A significant amount of acute neurological injury and illnesses cared for in the PICU occurs in pediatric patients with primary non-neurologic diagnoses and multi-system illness [2, 4]. Specialized neurocritical focus and expertise is needed to move the field of pediatric neurocritical care forward, although there is simultaneously a requirement that neurocritical care be deeply integrated into the general pediatric critical care delivery.

How should pediatric neurocritical care move forward? There is tremendous interest and momentum in the field of pediatric neurocritical care. In addition to the need to develop expertise and evidence-based guidelines for targeted neurological diseases, pediatric neurocritical care should also encompass and address the need for monitoring, support, and protection of the brain during all varieties of acute critical illness. The potential role of specialized pediatric neurocritical care services or dedicated neurocritical care units and the development of pediatric neurointensivists are the subject of much discussion [1, 2, 4, 189-192]. Pediatric neurocritical care training programs have been proposed and described. These emphasize the benefit of broad cross-disciplinary training, including training in pediatric medicine, neurology, anesthesia, adult neurocritical and neurovascular, neurosurgical and pediatric critical care [190, 191, 193]. In addition, several models of pediatric neurocritical care delivery have been proposed. Among these is an idealized model of integrated pediatric and neurocritical care that adopts a broad perspective of "brain-oriented" critical care [194]. The most effective model may differ based on the needs and characteristics of the parent 
institution. Specialized pediatric neurocritical care services will need to be justified by demonstrating improved patient outcomes and favorable cost-benefit analyses before they can be widely adopted. In the meantime, the field of pediatric neurointensive care continues to grow in scope and depth, bringing increased attention to neurological injury and illness in the PICU.

Required Author Forms Disclosure forms provided by the authors are available with the online version of this article.

\section{References}

1. Kilbaugh TJ, Huh JW, Berg RA. Neurological injuries are common contributors to pediatric intensive care unit deaths: a wakeup call. Pediatr Crit Care Med 2011;12:601-602.

2. Bell MJ, Carpenter J, Au AK, et al. Development of a pediatric neurocritical care service. Neurocrit Care 2009;10:4-10.

3. Namachivayam P, Shann F, Shekerdemian L, et al. Three decades of pediatric intensive care: Who was admitted, what happened in intensive care, and what happened afterward. Pediatr Crit Care Med 2010;11:549-555.

4. Au AK, Carcillo JA, Clark RSB, Bell MJ. Brain injuries and neurological system failure are the most common proximate causes of death in children admitted to a pediatric intensive care unit. Pediatr Crit Care Med 2010;12(5):566-71.

5. Koch JD, Kernie SG. Protecting the future: neuroprotective strategies in the pediatric intensive care unit. Curr Opin Pediatr 2011;23:275-280.

6. Schneier AJ, Shields BJ, Hostetler SG, Xiang H, Smith GA. Incidence of pediatric traumatic brain injury and associated hospital resource utilization in the United States. Pediatrics 2006;118:483-492.

7. Luerssen TG, Klauber MR, Marshall LF. Outcome from head injury related to patient age. J Neurosurg 1988;68:409-416.

8. Anderson V, Spencer-Smith M, Wood A. Do children really recover better? Neurobehavioural plasticity after early brain insult. Brain 2011;134:2197-2221.

9. Anderson V, Jacobs R, Spencer-Smith M, et al. Does early age at brain insult predict worse outcome? Neuropsychological implications. J Pediatr Psychol 2010;35:716-727.

10. Holt RL, Mikati MA. Care for child development: basic science rationale and effects of interventions. Pediatr Neurol 2011;44:239-253

11. Giza CC, Prins ML. Is being plastic fantastic? Mechanisms of altered plasticity after developmental traumatic brain injury. Dev Neurosci 2006;28:364-379.

12. Ewing-Cobbs L, Prasad MR, Kramer L, et al. Late intellectual and academic outcomes following traumatic brain injury sustained during early childhood. J Neurosurg 2006;105(4 suppl):287296.

13. Laurent-Vannier A, Brugel DG, De Agostini M. Rehabilitation of brain-injured children. Childs Nerv Syst 2000;16:760-764.

14. Gerrard-Morris A, Taylor HG, Yeates KO, et al. Cognitive development after traumatic brain injury in young children. J Inter Neuropsych Soc 2010;16:157-168.

15. Ewing-Cobbs L, Prasad MR, Swank P, et al. Social communication in young children with traumatic brain injury: Relations with corpus callosum morphometry. Int J Dev Neurosci 2011. doi:10.1016/j.ijdevneu.2011.07.004.
16. Koskiniemi M, Kyykkä T, Nybo T, Jarho L. Long-term outcome after severe brain injury in preschoolers is worse than expected. Arch Pediatr Adolesc Med 1995;149:249-254.

17. Keenan HT, Runyan DK, Marshall SW, Nocera MA, Merten DF, Sinal SH. A population-based study of inflicted traumatic brain injury in young children. JAMA 2003;290:621-626.

18. Keenan HT, Bratton SL. Epidemiology and outcomes of pediatric traumatic brain injury. Dev Neurosci 2006;28:256-263.

19. Keenan HT, Hooper SR, Wetherington CE, Nocera M, Runyan DK. Neurodevelopmental consequences of early traumatic brain injury in 3-year-old children. Pediatrics 2007;119:e616-e623.

20. Barlow KM, Thomson E, Johnson D, Minns RA. Late neurologic and cognitive sequelae of inflicted traumatic brain injury in infancy. Pediatrics 2005;116:e174-e85.

21. Duhaime AC, Christian C, Moss E, Seidl T. Long-term outcome in infants with the shaking-impact syndrome. Pediatr Neurosurg 1996;24:292-298.

22. Case ME. Inflicted traumatic brain injury in infants and young children. Brain Pathol 2008;18:571-582.

23. Ichord RN, Naim M, Pollock AN, Nance ML, Margulies SS, Christian CW. Hypoxic-ischemic injury complicates inflicted and accidental traumatic brain injury in young children: the role of diffusion-weighted imaging. J Neurotrama 2007;24:106-118.

24. Hymel KP, Makoroff KL, Laskey AL, Conaway MR, Blackman JA. Mechanisms, clinical presentations, injuries, and outcomes from inflicted versus noninflicted head trauma during infancy: results of a prospective, multicentered, comparative study. Pediatrics 2007;119:922-929.

25. Zimmerman RA, Bilaniuk LT, Farina L. Non-accidental brain trauma in infants: diffusion imaging, contributions to understanding the injury process. J Neuroradiol 2007;34:109-114.

26. Barnes PD. Imaging of nonaccidental injury and the mimics: issues and controversies in the era of evidence-based medicine. Radiol Clin North Am 2011;49:205-229.

27. Vinchon M, de Foort-Dhellemmes S, Desurmont M, Delestret I. Confessed abuse versus witnessed accidents in infants: comparison of clinical, radiological, and ophthalmological data in corroborated cases. Childs Nerv Syst 2010;26:637-645.

28. Shore PM, Berger RP, Varma S, et al. Cerebrospinal fluid biomarkers versus glasgow coma scale and glasgow outcome scale in pediatric traumatic brain injury: the role of young age and inflicted injury. J Neurotrauma 2007;24:75-86.

29. Cousar JL, Lai Y, Marco CD, et al. Heme oxygenase 1 in cerebrospinal fluid from infants and children after severe traumatic brain injury. Dev Neurosci 2006;28:342-347.

30. Beers SR, Berger RP, Adelson PD. Neurocognitive outcome and serum biomarkers in inflicted versus non-inflicted traumatic brain injury in young children. J Neurotrauma 2007;24:97-105.

31. Berger RP, Dulani T, Adelson PD, Leventhal JM, Richichi R, Kochanek PM. Identification of inflicted traumatic brain injury in well-appearing infants using serum and cerebrospinal markers: a possible screening tool. Pediatrics 2006;117:325-332.

32. Salonia R, Empey PE, Poloyac SM, et al. Endothelin-1 is increased in cerebrospinal fluid and associated with unfavorable outcomes in children after severe traumatic brain injury. J Neurotrauma 2010;27:1819-1825.

33. Berger RP, Ta'asan S, Rand A, Lokshin A, Kochanek P. Multiplex assessment of serum biomarker concentrations in well-appearing children with inflicted traumatic brain injury. Pediatr Res 2009;65:97-102.

34. Berger RP, Adelson PD, Richichi R, Kochanek PM. Serum biomarkers after traumatic and hypoxemic brain injuries: insight into the biochemical response of the pediatric brain to inflicted brain injury. Dev Neurosci 2006;28:327-335.

35. Filippidis AS, Papadopoulos DC, Kapsalaki EZ, Fountas KN. Role of the S100B serum biomarker in the treatment of children 
suffering from mild traumatic brain injury. Neurosurgical Focus 2010;29:E2.

36. Emeriaud G, Pettersen G, Ozanne B. Pediatric traumatic brain injury: an update. Curr Opin Anaesthesiol 2011;24:307-313.

37. Adelson PD, Srinivas R, Chang Y, Bell M, Kochanek PM. Cerebrovascular response in children following severe traumatic brain injury. Childs Nerv Syst 2011;27(9):1465-1476.

38. Duhaime A-C, Durham S. Traumatic brain injury in infants: the phenomenon of subdural hemorrhage with hemispheric hypodensity ("Big Black Brain"). Prog Brain Res 2007;161:293-302.

39. Giza CC, Mink RB, Madikians A. Pediatric traumatic brain injury: not just little adults. Curr Opin Crit Care 2007;13:143152.

40. Aldrich EF, Eisenberg HM, Saydjari C, et al. Diffuse brain swelling in severely head-injured children. A report from the NIH Traumatic Coma Data Bank. J Neurosurg 1992;76:450-454.

41. Kochanek PM. Pediatric traumatic brain injury: quo vadis? Dev. Neurosci 2006;28:244-255.

42. Adelson PD. Hypothermia following pediatric traumatic brain injury. J Neurotrauma 2009;26:429-436.

43. Snoek JW, Minderhoud JM, Wilmink JT. Delayed deterioration following mild head injury in children. Brain 1984;107(pt 1):1536.

44. Muizelaar JP, Ward JD, Marmarou A, Newlon PG, Wachi A. Cerebral blood flow and metabolism in severely head-injured children. Part 2: Autoregulation. J Neurosurg 1989;71:72-76.

45. Bruce DA, Alavi A, Bilaniuk L, Dolinskas C, Obrist W, Uzzell B. Diffuse cerebral swelling following head injuries in children: the syndrome of "malignant brain edema." J Neurosurg 1981;54:170-178.

46. Zwienenberg M, Muizelaar JP. Severe pediatric head injury: the role of hyperemia revisited. J Neurotrauma 1999;16:937-943.

47. Adelson PD, Clyde B, Kochanek PM, Wisniewski SR, Marion DW, Yonas H. Cerebrovascular response in infants and young children following severe traumatic brain injury: a preliminary report. Pediatr Neurosurg 1997;26:200-207.

48. Sharples PM, Stuart AG, Matthews DS, Aynsley-Green A, Eyre JA. Cerebral blood flow and metabolism in children with severe head injury. Part 1: Relation to age, Glasgow coma score, outcome, intracranial pressure, and time after injury. J Neurol Neurosurg Psychiatry 1995;58:145-152.

49. Philip S, Chaiwat O, Udomphorn Y, et al. Variation in cerebral blood flow velocity with cerebral perfusion pressure $>40 \mathrm{~mm} \mathrm{Hg}$ in 42 children with severe traumatic brain injury. Crit Care Med 2009;37:2973-2978.

50. Philip S, Udomphorn Y, Kirkham FJ, Vavilala MS. Cerebrovascular pathophysiology in pediatric traumatic brain injury. J Trauma 2009;67(Supp):S128-S134.

51. Coats B, Margulies SS. Material properties of human infant skull and suture at high rates. J Neurotrauma 2006;23:1222-1232.

52. Margulies SS, Thibault KL. Infant skull and suture properties: measurements and implications for mechanisms of pediatric brain injury. J Biomech Eng 2000;122:364-371.

53. Ibrahim NG, Margulies SS. Biomechanics of the toddler head during low-height falls: an anthropomorphic dummy analysis. J Neurosurg Pediatr 2010;6:57-68.

54. Bittigau P, Sifringer M, Felderhoff-Mueser U, Ikonomidou C. Apoptotic neurodegeneration in the context of traumatic injury to the developing brain. Exp Toxicol Pathol 2004;56:83-89.

55. Hansen HH, Briem T, Dzietko M, et al. Mechanisms leading to disseminated apoptosis following NMDA receptor blockade in the developing rat brain. Neurobiol Dis 2004;16:440-453.

56. Satchell MA, Lai Y, Kochanek PM, et al. Cytochrome c, a biomarker of apoptosis, is increased in cerebrospinal fluid from infants with inflicted brain injury from child abuse. J Cereb Blood Flow Metab 2005;25:919-927.
57. Berger RP, Pierce MC, Wisniewski SR, et al. Neuron-specific enolase and S100B in cerebrospinal fluid after severe traumatic brain injury in infants and children. Pediatrics 2002;109:E31.

58. Berger RP, Bazaco MC, Wagner AK, Kochanek PM, Fabio A. Trajectory analysis of serum biomarker concentrations facilitates outcome prediction after pediatric traumatic and hypoxemic brain injury. Dev Neurosci 2010;32:396-405.

59. Fraser DD, Close TE, Rose KL, et al. Severe traumatic brain injury in children elevates glial fibrillary acidic protein in cerebrospinal fluid and serum. Pediatr Crit Care Med 2011;12:319 324.

60. Vavilala MS, Lee LA, Boddu K, et al. Cerebral autoregulation in pediatric traumatic brain injury. Pediatr Crit Care Med 2004;5:257263.

61. Vavilala MS, Muangman S, Tontisirin N, et al. Impaired cerebral autoregulation and 6-month outcome in children with severe traumatic brain injury: preliminary findings. Dev Neurosci 2006;28:348-353.

62. Figaji AA, Zwane E, Fieggen AG, et al. Pressure autoregulation, intracranial pressure, and brain tissue oxygenation in children with severe traumatic brain injury. J Neurosurg Pediatr 2009;4:420-428.

63. Tontisirin N, Armstead W, Waitayawinyu P, et al. Change in cerebral autoregulation as a function of time in children after severe traumatic brain injury: a case series. Childs Nerv Syst 2007;23:1163-1169.

64. Freeman SS, Udomphorn Y, Armstead WM, Fisk DM, Vavilala MS. Young age as a risk factor for impaired cerebral autoregulation after moderate to severe pediatric traumatic brain injury. Anesthesiology 2008;108:588-595.

65. Vavilala MS, Muangman S, Waitayawinyu P, et al. Neurointensive care; impaired cerebral autoregulation in infants and young children early after inflicted traumatic brain injury: a preliminary report. J Neurotrauma 2007;24:87-96.

66. Sorrentino E, Budohoski KP, Kasprowicz M, et al. Critical thresholds for transcranial Doppler indices of cerebral autoregulation in traumatic brain injury. Neurocrit Care 2011;14:188-193.

67. Brady KM, Shaffner DH, Lee JK, et al. Continuous monitoring of cerebrovascular pressure reactivity after traumatic brain injury in children. Pediatrics 2009;124:e1205-e1212.

68. Chaiwat O, Sharma D, Udomphorn Y, Armstead WM, Vavilala MS. Cerebral hemodynamic predictors of poor 6-month Glasgow Outcome Score in severe pediatric traumatic brain injury. J Neurotrauma 2009;26:657-663.

69. Adelson PD, Bratton SL, Carney NA, et al. Guidelines for the acute medical management of severe traumatic brain injury in infants, children, and adolescents. Chapter 8 . Cerebral perfusion pressure. Pediatr Crit Care Med 2003;4 (3 Suppl):S31-S33.

70. Chambers IR, Stobbart L, Jones PA, et al. Age-related differences in intracranial pressure and cerebral perfusion pressure in the first 6 hours of monitoring after children's head injury: association with outcome. Childs Nerv Syst 2005;21:195-199.

71. Vavilala MS, Bowen A, Lam AM, et al. Blood pressure and outcome after severe pediatric traumatic brain injury. J Trauma 2003;55:1039-1044.

72. Narotam P, Burjonrappa S, Raynor S, Rao M, Taylon C. Cerebral oxygenation in major pediatric trauma: its relevance to trauma severity and outcome. J Pediatr Surg 2006;41:505-513.

73. Figaji AA, Fieggen AG, Argent AC, LeRoux PD, Peter JC. Does adherence to treatment targets in children with severe traumatic brain injury avoid brain hypoxia? A brain tissue oxygenation study. Neurosurg 2008;63:83-92.

74. Figaji AA, Zwane E, Fieggen AG, Peter JC, LeRoux PD. Acute clinical grading in pediatric severe traumatic brain injury and its association with subsequent intracranial pressure, cerebral 
perfusion pressure, and brain oxygenation. Neurosurgical Focus 2008;25:E4.

75. Figaji AA, Fieggen AG, Argent AC, Le Roux PD, Peter JC. Intracranial pressure and cerebral oxygenation changes after decompressive craniectomy in children with severe traumatic brain injury. Acta Neurochir Suppl 2008;102:77-80.

76. Ushewokunze S, Sgouros S. Brain tissue oxygenation changes in children during the first $24 \mathrm{~h}$ following head injury. Childs Nerv Syst 2009;25:341-345.

77. Figaji AA, Zwane E, Thompson C, et al. Brain tissue oxygen tension monitoring in pediatric severe traumatic brain injury. Childs Nerv Syst 2009;25:1335-1343.

78. Figaji AA, Zwane E, Graham Fieggen A, Argent AC, Le Roux $\mathrm{PD}$, Peter JC. The effect of increased inspired fraction of oxygen on brain tissue oxygen tension in children with severe traumatic brain injury. Neurocrit Care 2010;12:430-437.

79. Stiefel MF, Udoetuk JD, Storm PB, et al. Brain tissue oxygen monitoring in pediatric patients with severe traumatic brain injury. J Neurosurg 2006;105(4 Suppl):281-286.

80. Figaji AA, Zwane E, Thompson C, et al. Brain tissue oxygen tension monitoring in pediatric severe traumatic brain injury. Childs Nerv Syst 2009;25:1325-1333.

81. Shiozaki T, Sugimoto H, Taneda M, et al. Effect of mild hypothermia on uncontrollable intracranial hypertension after severe head injury. J Neurosurg 1993;79:363-368.

82. Biswas AK, Bruce DA, Sklar FH, Bokovoy JL, Sommerauer JF. Treatment of acute traumatic brain injury in children with moderate hypothermia improves intracranial hypertension. Crit Care Med 2002;30:2742-2751

83. Shankaran S, Laptook AR, Ehrenkranz RA, et al. Whole-body hypothermia for neonates with hypoxic-ischemic encephalopathy. N Engl J Med 2005;353:1574-1584

84. Natale JE, Joseph JG, Helfaer MA, Shaffner DH. Early hyperthermia after traumatic brain injury in children: risk factors, influence on length of stay, and effect on short-term neurologic status. Crit Care Med 2000;28:2608-2615.

85. Clifton GL, Miller ER, Choi SC, et al. Lack of effect of induction of hypothermia after acute brain injury. N Engl J Med 2001;344:556563.

86. Clifton GL, Drever P, Valadka A, Zygun D, Okonkwo D. Multicenter trial of early hypothermia in severe brain injury. J Neurotrauma 2009;26:393-397.

87. Hutchison JS, Ward RE, Lacroix J, et al. Hypothermia therapy after traumatic brain injury in children. N Engl J Med 2008;358:24472456.

88. Hutchison JS, Frndova H, Lo T-YM, Guerguerian A-M, Hypothermia Pediatric Head Injury Trial Investigators, Canadian Critical Care Trials Group. Impact of hypotension and low cerebral perfusion pressure on outcomes in children treated with hypothermia therapy following severe traumatic brain injury: a post hoc analysis of the Hypothermia Pediatric Head Injury Trial. Dev Neurosci 2010;32:406-412.

89. Suárez EP, González AS, Díaz CP, Salido AG, de Azagra Garde AM, Flores JC. Decompressive craniectomy in 14 children with severe head injury: clinical results with long-term follow-up and review of the literature. J Trauma 2011;71:133-140.

90. Thomale U-W, Graetz D, Vajkoczy P, Sarrafzadeh AS. Severe traumatic brain injury in children - a single center experience regarding therapy and long-term outcome. Childs Nerv Syst 2010;26:1563-1573.

91. Adamo MA, Drazin D, Waldman JB. Decompressive craniectomy and postoperative complication management in infants and toddlers with severe traumatic brain injuries. J Neurosurg Pediatr 2009;3:334-339.

92. Jagannathan J, Okonkwo DO, Dumont AS, et al. Outcome following decompressive craniectomy in children with severe traumatic brain injury: a 10-year single-center experience with long-term follow up. J Neurosurg 2007;106(4 Suppl):268-275.

93. Josan VA, Sgouros S. Early decompressive craniectomy may be effective in the treatment of refractory intracranial hypertension after traumatic brain injury. Childs Nerv Syst 2006;22:12681274.

94. Rutigliano D, Egnor MR, Priebe CJ, et al. Decompressive craniectomy in pediatric patients with traumatic brain injury with intractable elevated intracranial pressure. J Pediatr Surg 2006;41:83-87.

95. Figaji AA, Fieggen AG, Argent A, Peter JC. Surgical treatment for "brain compartment syndrome" in children with severe head injury. S Afr Med J 2006;96(9 Pt 2):969-975.

96. Mukherjee KK, Mohindra S, Gupta SK, Gupta R, Khosla VK. True hemicranial decompression for severe pediatric cranial trauma: a short series of 4 cases and literature review. Surg Neurol 2006;66:305-310.

97. Taylor A, Butt W, Rosenfeld J, et al. A randomized trial of very early decompressive craniectomy in children with traumatic brain injury and sustained intracranial hypertension. Childs Nerv Syst 2001;17:154-162.

98. Güresir E, Schuss P, Seifert V, Vatter H. Decompressive craniectomy in children. Single center series and systematic review. Neurosurgery 2011. doi:10.1227/NEU.0b013e318237a6a6.

99. Figaji AA, Fieggen AG, Sandler SJI, Argent AC, Le Roux PD, Peter JC. Intracranial pressure and cerebral oxygenation changes after decompressive craniectomy in a child with traumatic brain swelling. Childs Nerv Syst 2007;23:1331-1335.

100. Cooper DJ, Rosenfeld JV, Murray L, et al. Decompressive craniectomy in diffuse traumatic brain injury. $\mathrm{N}$ Engl $\mathrm{J}$ Med 2011;364:1493-1502.

101. Jordan LC, Hillis AE. Challenges in the diagnosis and treatment of pediatric stroke. Nat Rev Neurol 2011;7:199-208.

102. Agrawal N, Johnston SC, Wu YW, Sidney S, Fullerton HJ. Imaging data reveal a higher pediatric stroke incidence than prior US estimates. Stroke 2009;40:3415-3421.

103. Lynch JK, Hirtz DG, deVeber G, Nelson KB. Report of the National Institute of Neurological Disorders and Stroke workshop on perinatal and childhood stroke. In: Pediatrics 2002;109(1):116-123.

104. Broderick J, Talbot GT, Prenger E, Leach A, Brott T. Stroke in children within a major metropolitan area: the surprising importance of intracerebral hemorrhage. J Child Neurol 1993;8:250 255.

105. Armstrong-Wells J, Johnston SC, Wu YW, Sidney S, Fullerton HJ. Prevalence and predictors of perinatal hemorrhagic stroke: Results from the Kaiser Pediatric Stroke Study. Pediatrics 2009;123:823-828.

106. Fullerton HJ, Wu YW, Zhao S, Johnston SC. Risk of stroke in children: ethnic and gender disparities. Neurology 2003;61:189194.

107. Statler KD, Dong L, Nielsen DM, Bratton SL. Pediatric stroke: clinical characteristics, acute care utilization patterns, and mortality. Childs Nerv Syst 2011;27:565-573.

108. Cárdenas JF, Rho JM, Kirton A. Pediatric stroke. Childs Nerv Syst 2011;27:1375-1390.

109. Amlie-Lefond C, Sébire G, Fullerton HJ. Recent developments in childhood arterial ischaemic stroke. The Lancet Neurol 2008;7:425-435.

110. Perkins E, Stephens J, Xiang H, Lo W. The cost of pediatric stroke acute care in the United States. Stroke 2009;40:2820 2827.

111. Srinivasan J, Miller SP, Phan TG, Mackay MT. Delayed Recognition of Initial Stroke in Children: Need for Increased Awareness. Pediatrics 2009;124:e227-e234.

112. Gabis LV, Yangala R, Lenn NJ. Time lag to diagnosis of stroke in children. Pediatrics 2002;110:924-928. 
113. McGlennan C, Ganesan V. Delays in investigation and management of acute arterial ischaemic stroke in children. Dev Med Child Neurol 2008;50:537-540.

114. Rafay MF, Pontigon AM, Chiang J, et al. Delay to diagnosis in acute pediatric arterial ischemic stroke. Stroke 2008;40:58-64.

115. Zimmer JA, Garg BP, Williams LS, Golomb MR. Age-related variation in presenting signs of childhood arterial ischemic stroke. Pediatr Neurol 2007;37:171-175.

116. Hartman AL, Lunney KM, Serena JE. Pediatric stroke: do clinical factors predict delays in presentation? J Pediatr 2009;154:727732.

117. Rafay MF, Pontigon A-M, Chiang J, et al. Delay to diagnosis in acute pediatric arterial ischemic stroke. Stroke 2009;40:58-64.

118. Steinlin M, Pfister I, Pavlovic J, et al. The first three years of the Swiss Neuropaediatric Stroke Registry (SNPSR): a population-based study of incidence, symptoms and risk factors. Neuropediatrics 2005;36:9097.

119. Braun KPJ, Kappelle LJ, Kirkham FJ, deVeber G. Diagnostic pitfalls in paediatric ischaemic stroke. Dev Med Child Neurol 2006;48:985-990.

120. Shellhaas RA, Smith SE, O'Tool E, Licht DJ, Ichord RN. Mimics of childhood stroke: characteristics of a prospective cohort. Pediatrics 2006;118:704-709.

121. Abend NS, Beslow LA, Smith SE, et al. Seizures as a presenting symptom of acute arterial ischemic stroke in childhood. J Pediatr 2011;159:479-483.

122. Singh RK, Zecavati N, Singh J, et al. Seizures in acute childhood stroke. J Pediatr 2011. doi:10.1016/j.jpeds.2011.07.048.

123. Abend NS, Gutierrez-Colina AM, Topjian AA, et al. Nonconvulsive seizures are common in critically ill children. Neurology 2011;76:1071-1077.

124. Szaflarski JP, Rackley AY, Kleindorfer DO, et al. Incidence of seizures in the acute phase of stroke: a population-based study. Epilepsia 2008;49:974-981.

125. Lanska MJ, Lanska DJ, Horwitz SJ, Aram DM. Presentation, clinical course, and outcome of childhood stroke. Pediatr Neurol 1991;7:333-341.

126. Monagle P, Chalmers E, Chan A, et al. Antithrombotic therapy in neonates and children: American College of Chest Physicians Evidence-Based Clinical Practice Guidelines (8th Edition). Chest 2008;133(6 Suppl):887S-968S.

127. Roach ES, Golomb MR, Adams R, et al. Management of stroke in infants and children: a scientific statement from a special writing group of the American Heart Association Stroke Council and the Council on Cardiovascular Disease in the Young. Stroke 2008;39:2644-2691.

128. Eleftheriou D, Ganesan V. Controversies in childhood arterial ischemic stroke and cerebral venous sinus thrombosis. Expert Rev Cardiovasc Ther 2009;7:853-861.

129. Ichord RN, Bastian R, Abraham L, et al. Interrater reliability of the Pediatric National Institutes of Health Stroke Scale (PedNIHSS) in a multicenter study. Stroke 2011;42:613-617.

130. Fullerton H, Lynch JK, deVeber G. The call for multicenter studies of pediatric stroke. Stroke 2006;37:330-331.

131. Amlie-Lefond C, deVeber G, Chan AK, et al. Use of alteplase in childhood arterial ischaemic stroke: a multicentre, observational, cohort study. Lancet Neurol 2009;8:530-536.

132. Jordan LC, Rafay MF, Smith SE, et al. antithrombotic treatment in neonatal cerebral sinovenous thrombosis: results of the International Pediatric Stroke Study. J Pediatr 2010;156:704710 .

133. Andrew M, Vegh P, Johnston M, Bowker J, Ofosu F, Mitchell L. Maturation of the hemostatic system during childhood. Blood 1992;80:1998-2005.

134. Lo WD. Childhood hemorrhagic stroke: an important but understudied problem. J Child Neurol 2011;26:1174-1185.
135. Beslow LA, Licht DJ, Smith SE, et al. Predictors of outcome in childhood intracerebral hemorrhage: a prospective consecutive cohort study. Stroke 2010;41:313-318.

136. Al-Jarallah A, Al-Rifai MT, Riela AR, Roach ES. Nontraumatic brain hemorrhage in children: etiology and presentation. J Child Neurol 2000;15:284-289.

137. Amlie-Lefond C, Bernard TJ, Sebire G, et al. Predictors of cerebral arteriopathy in children with arterial ischemic stroke: results of the International Pediatric Stroke Study. Circulation 2009;119:1417-1423.

138. Fullerton HJ, Wu YW, Sidney S, Johnston SC. Risk of recurrent childhood arterial ischemic stroke in a population-based cohort: the importance of cerebrovascular imaging. Pediatrics 2007;119:495501.

139. Fox CK, Fullerton HJ. Recent advances in childhood arterial ischemic stroke. Curr Atheroscler Rep 2010;12:217-224.

140. Fullerton HJ, Elkind MSV, Barkovich AJ, et al. The Vascular Effects of Infection in Pediatric Stroke (VIPS) Study. J Child Neurol 2011;26:1101-110.

141. Mestrovic J, Kardum G, Sustic A, et al. Neurodevelopmental disabilities and quality of life after intensive care treatment. J Paediatr Child Health 2007;43:673-676.

142. Elison S, Shears D, Nadel S, Sahakian B, Garralda ME. Neuropsychological function in children following admission to paediatric intensive care: a pilot investigation. Intensive Care Med 2008;34:1289-1293.

143. Friedman D, Claassen J, Hirsch LJ. Continuous electroencephalogram monitoring in the intensive care unit. Anesth Analg 2009;109:506-523.

144. Jette N, Claassen J, Emerson RG, Hirsch LJ. Frequency and predictors of nonconvulsive seizures during continuous electroencephalographic monitoring in critically ill children. Arch Neurol 2006;63:1750-1755.

145. Claassen J, Mayer SA, Kowalski RG, Emerson RG, Hirsch LJ. Detection of electrographic seizures with continuous EEG monitoring in critically ill patients. Neurology 2004;62:17431748.

146. Vespa PM, Miller C, McArthur D, et al. Nonconvulsive electrographic seizures after traumatic brain injury result in a delayed, prolonged increase in intracranial pressure and metabolic crisis. Crit Care Med 2007;35:2830-2836.

147. Hahn CD. Nonconvulsive seizures among critically ill children: look and you shall find. Neurology 2011;76:1036-1037.

148. Abend NS, Dlugos DJ. Nonconvulsive status epilepticus in a pediatric intensive care unit. Pediatr Neurol 2007;37:165-170.

149. Yilmaz Y, Onultan O, Berber M. Nonconvulsive status epilepticus during childhood: clinical and electroencephalographic features. Turk J Pediatr 2008;50:449-455.

150. Saengpattrachai M, Sharma R, Hunjan A, et al. Nonconvulsive seizures in the pediatric intensive care unit: etiology, EEG, and brain imaging findings. Epilepsia 2006;47:1510-518.

151. Tay SKH, Hirsch LJ, Leary L, Jette N, Wittman J, Akman CI. Nonconvulsive status epilepticus in children: clinical and EEG characteristics. Epilepsia 2006;47:1504-509.

152. Williams K, Jarrar R, Buchhalter J. Continuous video-EEG monitoring in pediatric intensive care units. Epilepsia 2011;52:1130 1136.

153. Hyllienmark L, Amark P. Continuous EEG monitoring in a paediatric intensive care unit. Eur J Paediatr Neurol 2007;11:70-75.

154. Hosain SA, Solomon GE, Kobylarz EJ. Electroencephalographic patterns in unresponsive pediatric patients. Pediatr Neurol 2005;32:162-165.

155. Shahwan A, Bailey C, Shekerdemian L, Harvey AS. The prevalence of seizures in comatose children in the pediatric intensive care unit: a prospective video-EEG study. Epilepsia 2010;51:11981204. 
156. Abend NS, Topjian A, Ichord R, et al. Electroencephalographic monitoring during hypothermia after pediatric cardiac arrest. Neurology 2009;72:1931-1940.

157. Loepke AW. Developmental neurotoxicity of sedatives and anesthetics: a concern for neonatal and pediatric critical care medicine? Pediatr Crit Care Med 2010;11:217-226.

158. de Mos N, van Litsenburg RRL, McCrindle B, Bohn DJ, Parshuram CS. Pediatric in-intensive-care-unit cardiac arrest: incidence, survival, and predictive factors. Crit Care Med 2006;34:1209-1215.

159. Donoghue AJ, Nadkarni V, Berg RA, et al. Out-of-hospital pediatric cardiac arrest: an epidemiologic review and assessment of current knowledge. Ann Emerg Med 2005;46:512-522.

160. Reis AG, Nadkarni V, Perondi MB, Grisi S, Berg RA. A prospective investigation into the epidemiology of in-hospital pediatric cardiopulmonary resuscitation using the international Utstein reporting style. Pediatrics 2002;109:200-209.

161. Moler FW, Meert K, Donaldson AE, et al. In-hospital versus outof-hospital pediatric cardiac arrest: a multicenter cohort study. Crit Care Med 2009;37:2259-2267.

162. Bernard SA, Gray TW, Buist MD, et al. Treatment of comatose survivors of out-of-hospital cardiac arrest with induced hypothermia. N Engl J Med 2002;346:557-563.

163. Hypothermia after Cardiac Arrest Study Group. Mild therapeutic hypothermia to improve the neurologic outcome after cardiac arrest. N Engl J Med 2002;346:549-556.

164. Atkins DL, Everson-Stewart S, Sears GK, et al. Epidemiology and outcomes from out-of-hospital cardiac arrest in children: the Resuscitation Outcomes Consortium Epistry-Cardiac Arrest. Circulation 2009;119:1484-1491.

165. Samson RA, Nadkarni VM, Meaney PA, et al. Outcomes of inhospital ventricular fibrillation in children. $N$ Engl J Med 2006;354:2328-2339.

166. Kim Y-M, Yim H-W, Jeong S-H, Klem ML, Callaway CW. Does therapeutic hypothermia benefit adult cardiac arrest patients presenting with non-shockable initial rhythms? A systematic review and meta-analysis of randomized and non-randomized studies. Resuscitation 2011. doi:10.1016/j.resuscitation.2011.07.031.

167. Dumas F, Grimaldi D, Zuber B, et al. Is hypothermia after cardiac arrest effective in both shockable and nonshockable patients? Insights from a large registry. Circulation 2011;123:877-886.

168. Fink EL, Clark RSB, Kochanek PM, Bell MJ, Watson RS. A tertiary care center's experience with therapeutic hypothermia after pediatric cardiac arrest. Pediatr Crit Care Med 2010;11:66-74.

169. Doherty DR, Parshuram CS, Gaboury I, et al. Hypothermia therapy after pediatric cardiac arrest. Circulation 2009;119:1492-1500.

170. Moler FW, Donaldson AE, Meert K, et al. Multicenter cohort study of out-of-hospital pediatric cardiac arrest. Criti Care Med 2011;39:141-149.

171. Meert KL, Donaldson A, Nadkarni V, et al. Multicenter cohort study of in-hospital pediatric cardiac arrest. Pediatr Crit Care Med 2009; 10:544-553.

172. Scholefield BR, Duncan HP, Morris KP. Survey of the use of therapeutic hypothermia post cardiac arrest. Arch Dis Child 2010;95:796-799.

173. Haque IU, LaTour MC, Zaritsky AL. Pediatric critical care community survey of knowledge and attitudes toward therapeutic hypothermia in comatose children after cardiac arrest. Pediatr Crit Care Med 2006;7:7-14.

174. Delmo Walter EM, Alexi-Meskishvili V, Huebler M, et al. Rescue extracorporeal membrane oxygenation in children with refractory cardiac arrest. Interact Cardiovasc Thorac Surg 2011;12:929934.

175. Sivarajan VB, Best D, Brizard CP, Shekerdemian LS, d'Udekem Y, Butt W. Duration of resuscitation prior to rescue extracorporeal membrane oxygenation impacts outcome in children with heart disease. Intensive Care Med 2011;37:853-860.

176. Kane DA, Thiagarajan RR, Wypij D, et al. Rapid-response extracorporeal membrane oxygenation to support cardiopulmonary resuscitation in children with cardiac disease. Circulation 2010;122(11 Suppl):S241-S248.

177. Kelly RB, Harrison RE. Outcome predictors of pediatric extracorporeal cardiopulmonary resuscitation. Pediatr Cardiol 2010;31:626-633.

178. Prodhan P, Fiser RT, Dyamenahalli U, et al. Outcomes after extracorporeal cardiopulmonary resuscitation (ECPR) following refractory pediatric cardiac arrest in the intensive care unit. Resuscitation 2009;80:1124-1129.

179. Lequier L, Joffe AR, Robertson CMT, et al. Two-year survival, mental, and motor outcomes after cardiac extracorporeal life support at less than five years of age. J Thorac Cardiovasc Surg 2008;136:976-983.

180. Huang S-C, Wu E-T, Chen Y-S, et al. Extracorporeal membrane oxygenation rescue for cardiopulmonary resuscitation in pediatric patients. Crit Care Med 2008;36:1607-1613.

181. Alsoufi B, Al-Radi OO, Nazer RI, et al. Survival outcomes after rescue extracorporeal cardiopulmonary resuscitation in pediatric patients with refractory cardiac arrest. J Thorac Cardiovasc Surg 2007;134:952-959.

182. Thourani VH, Kirshbom PM, Kanter KR, et al. Venoarterial extracorporeal membrane oxygenation (VA-ECMO) in pediatric cardiac support. Ann Thorac Surg 2006;82:138-145.

183. Thiagarajan RR, Laussen PC, Rycus PT, Bartlett RH, Bratton SL. Extracorporeal membrane oxygenation to aid cardiopulmonary resuscitation in infants and children. Circulation 2007;116:16931700.

184. Raymond TT, Cunnyngham CB, Thompson MT, et al. Outcomes among neonates, infants, and children after extracorporeal cardiopulmonary resuscitation for refractory inhospital pediatric cardiac arrest: a report from the National Registry of Cardiopulmonary Resuscitation. Pediatr Crit Care Med 2010;11:362-371.

185. Tajik M, Cardarelli MG. Extracorporeal membrane oxygenation after cardiac arrest in children: what do we know? Eur J Cardiothorac Surg 2008;33:409-417.

186. Barrett CS, Bratton SL, Salvin JW, Laussen PC, Rycus PT, Thiagarajan RR. Neurological injury after extracorporeal membrane oxygenation use to aid pediatric cardiopulmonary resuscitation. Pediatr Crit Care Med 2009;10:445-451.

187. Suarez JI, Zaidat OO, Suri MF, et al. Length of stay and mortality in neurocritically ill patients: impact of a specialized neurocritical care team. Crit Care Med 2004;32:2311-2317.

188. Rincon F, Mayer SA. Neurocritical care: a distinct discipline? Curr Opin Crit Care 2007;13:115-121.

189. Friess SH, Naim MY, Helfaer MA. Is pediatric neurointensive care a legitimate programmatic advancement to benefit our patients and our trainees, or others? Pediatr Crit Care Med 2010;11:758-760.

190. LaRovere KL, Riviello JJ. Emerging subspecialties in neurology: building a career and a field: pediatric neurocritical care. Neurology 2008;70:e89-e91.

191. Kochanek PM, Bell MJ, Bayir H. Quo vadis 2010? Carpe diem: challenges and opportunities in pediatric traumatic brain injury. Dev Neurosci 2010;32:335-342.

192. Spentzas T, Escue JE, Patters AB, Varelas PN. Brain tumor resection in children: neurointensive care unit course and resource utilization. Pediatr Crit Care Med 2010;11:718-722.

193. Scher M. Proposed cross-disciplinary training in pediatric neurointensive care. Pediatric Neurol 2008;39:1-5.

194. Tasker RC. Pediatric neurocritical care: is it time to come of age? Curr Opin in Pediatr 2009;21:724-730. 